\title{
Correspondence
}

\section{Advertisements by Malpractice Attorneys}

\section{Dear Editors:}

As a hospital risk manager who is aware of attorneys' advertisements in the Yellow Pages and on television, I cannot agree more with Thomas $\mathrm{E}$. Cargill's comments in the President's Column published in the December issue.

Not only do these ads create "unsavory images" of attorneys as well as pres ent physicians and other health care providers as errant caretakers, but they also neglect to caution the public as to how protracted and oftentimes emotionally taxing the process of litigation can be, with no guarantee of a favorable outcome for the plaintiff. Moreover, the public is not told about the cost which will inevitably be incurred in the course of litigation-a cost which, ultimately, must be born by society in general.

\section{Janice Rader \\ Risk Manager \\ St. Luke's Hospital \\ Bethlehem, Pennsylvania}

\section{Dear Editors:}

As a law student with experience in the health care system, I concur that malpractice lawyers' advertisements perpetuate misunderstanding and distrust between the professions.

Most physicians realize that patients involved in lawsuits may have a

"delayed" healing response. I have often seen patients not only waste precious time waiting for a settlement, but also develop new symptoms in hope of secondary gain.

These advertisements serve only to infuriate physicians and to confuse patients. I hope that the legal profession could regulate these advertisements in some manner.

\section{Thomas W. Bonekemper Quakertown, Pennsylvania}

\section{Dear Editors:}

Several months ago, 1 saw in a New York City newspaper an ad that asserted in bold letters: "Was your child (up to $19 \mathrm{yrs}$ old) brain damaged or injured at birth? 'You may be entitled to large Money Damages.' "It is the height of irresponsibility for an "officer of the court" to prey on a group of people who are already struggling with a hopeless diagnosis, by tantalizing them with the possibility of a satisfactory outlet for their anger as well as an escape from their own feelings of guilt (unjustified as they might be), especially when the likelihood is that they will only be frustrated again.

It behooves organizations such as the New York State Trial Lawyers Association (an organization of which the above-mentioned advertising lawyer proudly proclaims he is a member) to define the parameters of acceptable advertising, and to exert pressure on their members to conduct themselves accordingly.

1 applaud any attempt by the American Society of Law \& Medicine to set an example for other societies and organizations by developing standards for advertising which are morally, ethically and professionally appropriate.

Aviva M. Halpert, R.R.A.

Risk Management Coordinator

Hillcrest General Hospital

Flushing, New York

\section{Mr. Cargill responds}

I am encouraged by the comments that I received in response to my column in the December issue; there does seem to be a desire to control these advertisements in some way. The American Society of Law \& Medicine is considering the development of an ad hoc committee to examine the problems associated with advertising that promotes medical malpractice attorneys. The committee's primary goal would be to develop standards for such advertisements. Individ. uals who are interested in serving on the committee or who have opinions on the subject, are strongly encouraged to conract A. Edward Doudera, J.D., Executive Director, American Society of Law \& Medicine, 765 Commonwealth Ave., Boston, MA 02215.

\section{Quality of Care and Nurse Anesthetists}

Dear Editors:

In the article, Entrepreneurial Practice for Nurses: An Assessment of the Issues, published in the December issue, Profes- sor Nathan Hershey states that "a careful, extensive review of the relevant literature reveals no studies comparing the quality of services rendered by nurse anesthetists and anesthesiologists."

In fact, two reports on such studies have been published, both of which compared, by provider, the mortality rates related to use of anesthesia. ${ }^{1}$ The results of these studies indicate that there is no significant difference in the quality of care, measured by ourcome, whether delivered by anesthesiologists or nurse anesthetists. One study reported: "It was surprising that the stage of training of the anesthesiologist or administration of an anesthetic by a nurse anesthetist or anesthesiologist seemed to affect risk very little..." ${ }^{2}$ As an attorney who represents certified registered nurse anesthetists, $I$ recommend these studies to $\mathrm{Mr}$. Hershey and to your readers.

I would also point out that Mr. Hershey's speculation as to the reasons for the supposed lack of such studies, i.e., that they would reveal "the possible violation of licensing legislation," is groundless. The administration of anesthesia by CRNAs is legally within their scope of practice in every state of the nation. Thirty-five states, in fact, specifically recognize nurse anesthesia as the expanded practice of nursing, but no state requires supervision of nurse anes. thetists by an anesthesiologist. There is, therefore, no question of "possible violation of licensing legislation" in the administration of anesthesia by CRNAs.

Susan M. Jenkins, J.D.

Jenkins \& Kurz

Washington, D.C.

\section{References}

1. Forrest, Outcome-The Effect of the Pro. vider, in HEAlTH CARE DELIVERY in ANESTHESTA (Hirsch, Forrest, Orkin, Wollman, eds.) (G.F. Stickley Co., Philadelphia, Pa.) (1980). Bechtoldt, A., Committee on Anesthesia Srudy, Anesthesia Related Deaths, 1969-1976, NORTH CAROLina Medical Journal 42(4): 257 (April 1981).

2. Forrest, supra note 1, at 220.

Professor Hershey replies

I must take issue with Ms. Jenkins' response to my article. While the law generally permits nurse anesthetists to administer anesthetic agents, the nurse anestherist is not a fully independent provider of anesthesia services, in that 